\title{
OPINION
}

Joseph Sadek, MD, FRCPC, DABPN Mary Pyche, CSW, MSW

Scott Theriault, MD, FRCPC

Nicholas Delva, MD, FRCPC

Sonia Chehil, MD, FRCPC

David Pilon, PhD

Department of Psychiatry, Dalhousie

University, Halifax, NS

\section{A new suicide risk assessment tool in Nova Scotia, Canada}

Suicide is a major public health concern. In Canada, suicide is the ninth leading cause of death in all ages, with a rate of 10.3 deaths per 100,000 people. In Nova Scotia, Canada, 137 suicides were reported in 2016 [1]. Suicide risk assessment (SRA) and management are clinical competencies required for patient care. Strategies used for SRA include the use of formal self-report measures [2], personalized clinical interview however vital information about suicide risk may be missed during that unstructured assessment [3] and structured tool to supplement the clinical interview.
Manuscript submitted 18th December, 2019

Manuscript accepted 12th February, 2020

Clin Invest Med 2020; 43 (1): E30-34.

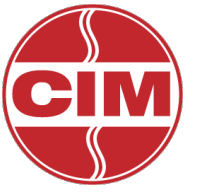

\section{Correspondence to:}

Joseph Sadek

Email: joseph.sadek@nshealth.ca 
Suicide is a major public health concern. In Canada, suicide is the ninth leading cause of death in all ages, with a rate of 10.3 deaths per 100,000 people. In Nova Scotia, Canada, 137 suicides were reported in 2016 [1]. Suicide risk assessment (SRA) and management are clinical competencies required for patient care. Strategies used for SRA include the use of formal self-report measures [2], personalized clinical interview however vital information about suicide risk may be missed during that unstructured assessment [3] and structured tool to supplement the clinical interview.

The debate around using suicide prediction tools and the methodology of risk prediction had not advanced meaningfully for many years [4]. A conventional approach to the development of SRA tools has been to collate likely risk factors for suicide, based on concepts of face or content validity. Tools such as the Beck Hopelessness Scale, the Suicide Intent Scale and the SAD PERSONS scale (acronym based on 10 suicide risk factors) continue to be used in several centers. Newer scales, such as the Columbia-Suicide Severity Rating Scale and the Suicide Probability Scale, are based on conventional approaches. One study has shown that the Columbia-Suicide Severity Rating Scale predicts future suicidal behavior with sensitivity and specificity of $67 \%$ and $76 \%$, respectively [5]. Relying solely on numerical results generated by structured instruments can be considered too simplistic a response for a highly complex assessment [6]. Critics continue to emphasize that empirically derived tools, such as the Manchester Self-harm Rule [7] and the Repeated Episodes of Self-harm score [8], which used more robust methodology in their development, are not strong enough for making a clinical decision [9-11]. There are recent suggestions of adopting a multistage screening approach, using improved analysis methods, calculating the net benefit and development of individualized treatment rules to develop new suicide prediction tool, but these approaches have not yet been developed [4].

To meet the recommendations of existing suicide prevention guidelines [5] and Accreditation Canada Standards, and to properly document the communication and management plan, a novel tool (Appendix A) has been created by our multidisciplinary working group. Available tools and the relevant literature were reviewed and our tool went through multiple stages of development before being tested in acute care. The tool went through several steps of testing, modification and refinement before being used across the province of Nova Scotia. Specific, mandatory SRA training was also provided to all clinicians working in the public mental health system in the province.

This new tool has many unique features: it contributes to a standardized SRA process; it allows for SRA information to be accessed in one convenient location throughout a patient's chart; and it facilitates communication of a patient's suicide risk and management plan with other healthcare providers. The tool also has important implications from a medicolegal viewpoint. The most common malpractice issue related to suicide is failure to provide protection to patients from killing themselves. The law recognizes that suicide is a complex issue and cannot be attributed to a single cause. The law also recognizes that there are no standards for its prediction; however, the law would consider the "foreseeability" concept. That means that when the court makes a decision, in many cases consideration is given to the clinician's ability to take an accurate history, recognize the relevant risk factors and prepare a treatment plan that will guard against completed suicide [12].

The new tool was designed to capture important validated risk and protective factors. Some risk factors are related to the mental status of the patient during the clinical interview (e.g., suicidal intent, intense emotions and hopelessness) and some are related to patient profile (e.g., previous attempts, mental illness and chronic medical illness). Additional areas of risk, such as the lack of support and poor response to treatment, were also added.

The tool also has a communication plan section to ensure that other providers involved in the care of the patient are aware of the suicide risk. Finally, a management plan section is available to allow clinicians to start an initial management plan based on their clinical judgment of the risk level. A space has been allocated to explain or elaborate on the rationale behind the clinical decision. The decisions made about suicide risk level are based solely on clinical judgment. Clinicians are provided with a summary of examples of different risk levels (Appendix B).

Our suicide risk assessment tool has a number of limitations. One limitation is the difficulty in accurately predicting the suicide risk; but this limitation is common in all tools. The management plan is concise; however, we suggest that clinicians should use it only as a starting point and expand on it based on their clinical judgement. Finally, patients with non-suicidal self-injuries are not clearly identified; however, the tool has one item that suggests following a patient care plan for chronic risk.

Our tool can be used to inform the clinical decisions of trained clinicians and in different clinical settings. It is not specific to Nova Scotia but can be used worldwide. 
APPENDIX A. Suicide risk assessment and intervention tool

Sulcide Plisk Assessment and Intervention Tool

Date

Time

Assessor

Reason: * MH Assessmect eAdmission/Translee/Dischange
Pationt Information

Diagnosis

- Acuse deberioration

\begin{tabular}{|c|c|c|}
\hline 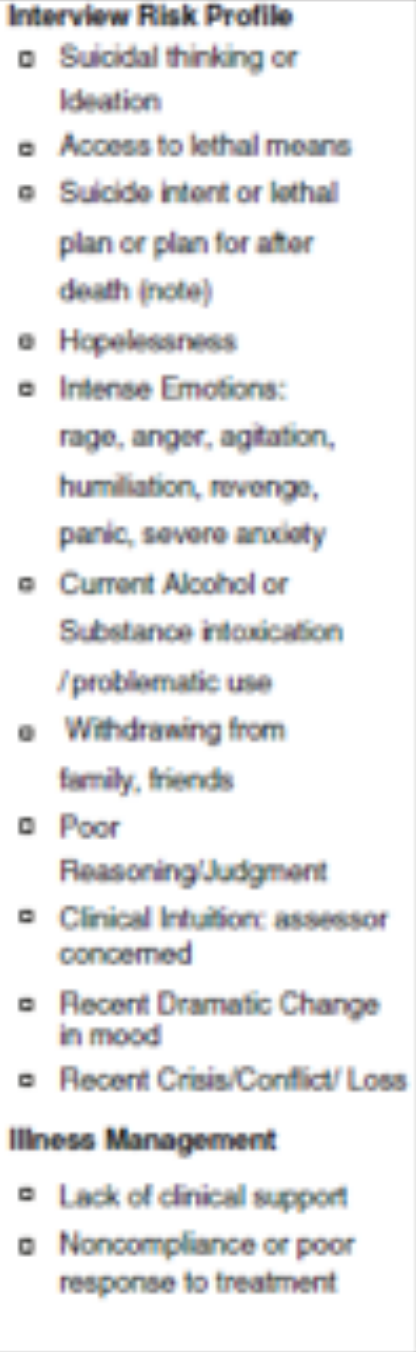 & 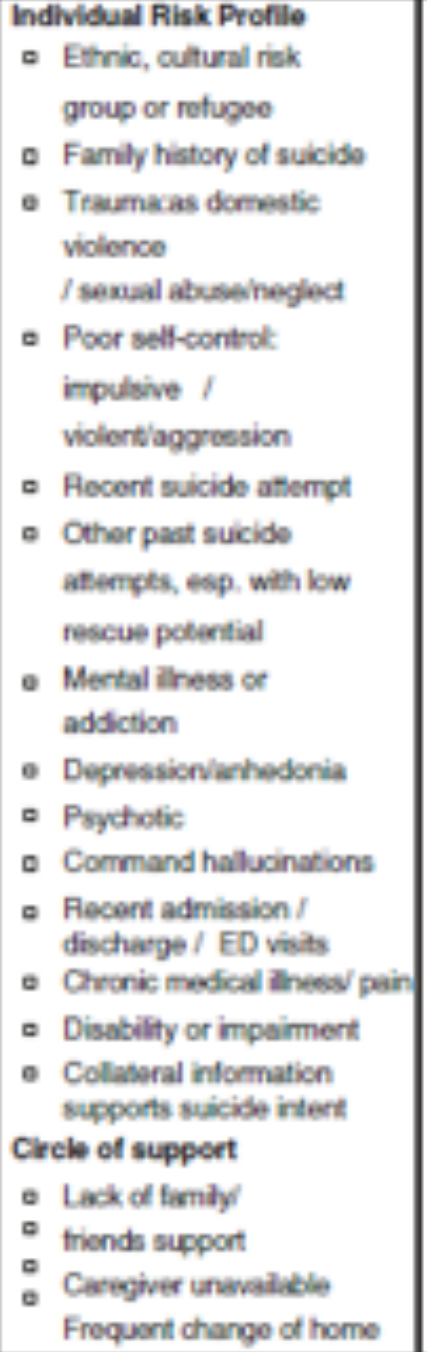 & 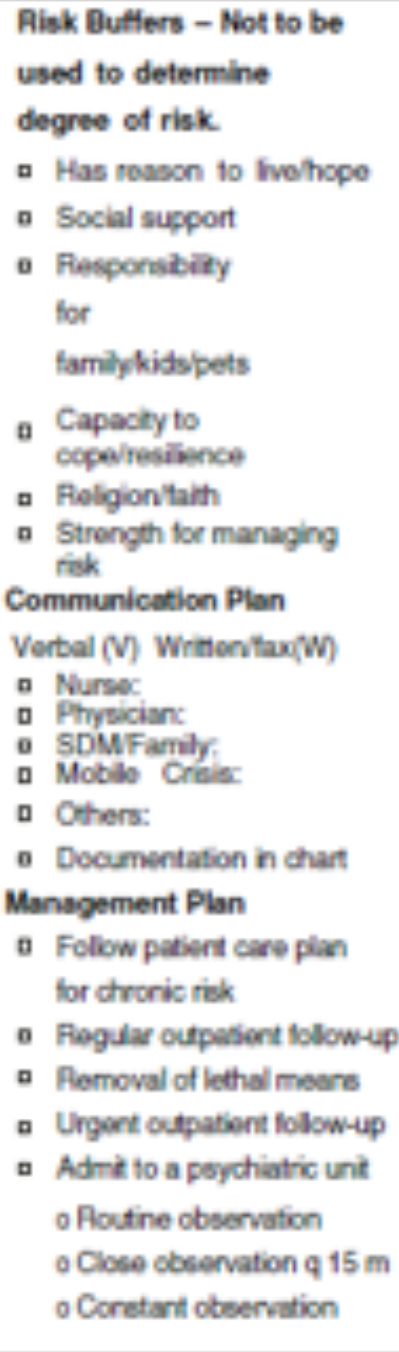 \\
\hline
\end{tabular}

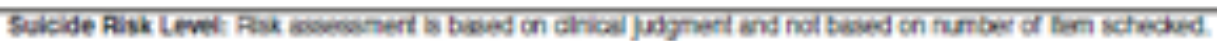
The cheodist is intended toguldo the clirical dodision cnily.

RISKLEVEL: a High D Moderate DLow Signahure:

Analysis of Risk, Comments and Collateral Intormatieg: 


\section{APPENDIX B. Breakdown of suicide risk levels}

\begin{tabular}{|c|c|c|}
\hline Level & Suicide risk monitoring level & Risk level \\
\hline 1 & $\begin{array}{l}\text { When there are no specific risk factors requiring intervention and } \\
\text { there are few active concerns about suicide. In cases of previously } \\
\text { established suicidal gestures or behaviors, low risk implies that there } \\
\text { are no new, treatable risk factors to target; the patient/client is at } \\
\text { "their baseline risk" } \\
\text { The patient/client may require follow-up monitoring of clinical status } \\
\text { and suicide risk if (but not limited to): } \\
\text { - Changes in life situation and/or mental status occur that may be } \\
\text { reasonably expected to change suicide risk } \\
\text { - Changes in care pathways or continuity occur (e.g., transition from a day } \\
\text { hospital to a community clinic setting) }\end{array}$ & Low \\
\hline 2 & $\begin{array}{l}\text { When there are some identified risk factors that may impact risk and } \\
\text { there is a need for a suicide plan to address risk factors. Suicide risk is } \\
\text { present but not imminent and, in the opinion of the health provider, } \\
\text { can be managed through current supports and ongoing clinical care. } \\
\text { In this circumstance the patient requires ongoing monitoring of suicide } \\
\text { risk, and the following shall be implemented: } \\
\text { - Suicide risk is formally assessed, and the assessment outcome is } \\
\text { appropriately documented } \\
\text { - A suicide risk monitoring and management plan is developed, } \\
\text { documented, communicated, implemented, and reviewed as clinically } \\
\text { indicated } \\
\text { - A change in suicide risk status is documented and appropriately } \\
\text { communicated } \\
\text { - The suicide risk level is documented and appropriately communicated, as } \\
\text { per policy }\end{array}$ & Moderate \\
\hline 3 & $\begin{array}{l}\text { When in the opinion of the health provider, suicide risk is high } \\
\text { (imminent). There are multiple risk factors that convey a strong degree } \\
\text { of risk and that a high level of intervention or monitoring is required. } \\
\text { Often this suggests that there is a subjective sense of urgency to } \\
\text { address the risk factors as quickly as possible. In this case the patient } \\
\text { requires increased monitoring of suicide risk, and the following shall } \\
\text { be implemented: } \\
\text { - The high level of suicide risk shall be appropriately documented and } \\
\text { communicated to all relevant providers and as clinically determined } \\
\text { within the patient's circle of care } \\
\text { - A suicide risk assessment, intervention, and monitoring protocol shall be } \\
\text { documented in the patient's individual care plan and other locations as } \\
\text { deemed appropriate by the clinical care team. This may require } \\
\text { application of constant, close, or other monitoring frameworks as } \\
\text { clinically determined } \\
\text { - The suicide risk assessment and monitoring plan shall be appropriately } \\
\text { communicated to all relevant care providers and such members of the } \\
\text { patient's circle of care as deemed appropriate by the responsible clinician } \\
\text { - The responsible clinician shall determine the appropriate level and } \\
\text { location of care based on their best clinical judgment } \\
\text { - Ongoing formal review of the patient's suicide risk status shall be } \\
\text { undertaken as deemed appropriate by the clinical care team }\end{array}$ & High \\
\hline
\end{tabular}




\section{References}

1. Public Health Agency of Canada. Suicide in Canada: Key statistics (infographic). Ottawa (ON): PHAC; modified Feb 2020. https://www.canada.ca/en/public-health/services/ publications/healthy-living/suicide-canada-key-statisticsinfographic.html

2. Brown GK. A Review of Suicide Assessment Measures for Intervention Research with Adults and Older Adults. National Institute of Mental Health (NIMH); 2000. https:// www.sprc.org/resources-programs/review-suicide-assessmentmeasures-intervention-research-adults-older-adults

3. Jobes DA, Eryman JR, Yufit RI. How clinicians assess suicide risk in adolescents and adults. Crisis Interv. 1995; 2:1-12

4. Kessler RC, Bossarte RM, Luedtke A, Zaslavsky AM, Zubizarreta JR. Suicide prediction models: a critical review of recent research with recommendations for the way forward. Mol Psychiatry. 2020; 25(1):168-79.

5. Bolton JM, et al. Suicide risk assessment and intervention in people with mental illness. Br Med J. 2015; 351:h4978.

6. Grant CL, Lusk JL. A multidisciplinary approach to therapeutic risk management of the suicidal patient. $J$ Multidiscip Healthc. 2015; 8:291-8.

7. Bilen K, Ponzer S, Ottosson C, Castrén M, Pettersson H. Deliberate self-harm patients in emergency department. Who will repeat and who will not? Validation and development of clinical decision rules. Emerg Med J. 2013; 30:650-6

8. Spittal MJ, Pirkis J, Miller M, et al. The repeated episodes of self-harm (RESH) score: a tool for predicting risk of future episodes of self-harm by hospital patients. J Affect Disord. 2014; 161:36-42.

9. Large M, Myles N, Myles H, et al. Suicide risk assessment among psychiatric inpatients: a systematic review and metaanalysis of high-risk categories. Psychol Med. 2018; 48:1119-27.

10. Mulder R, Newton-Howes G, Coid JW. The futility of risk prediction in psychiatry. Br J Psycbiatry. 2016; 209:271-2.

11. Owens D, Kelley R. Predictive properties of risk assessment instruments following self- harm. BrJ Psycbiatry. 2017; 210: 384-6.

12. Sher L. Suicide medical malpractice: an educational overview. Int J Adolesc Med Health. 2015; 27(2):203-6. 